\title{
Avaliação das Características Quali-Quantitativa das Águas do Rio Beem, Município de Humaitá-Amazonas
}

\section{Evaluation of Qualitative and Quantitative Characteristics of the Beem River Water, Municipality of Humaita-Amazon}

\author{
Klenna Lívia Gomes Peixoto; ${ }^{1}$ Harumy Sales Noguchi ${ }^{2} ;$ Anne Relvas Pereira ${ }^{3}$; Margarida Marchetto ${ }^{4}$ Aldecy de \\ Almeida Santos \\ ${ }^{1}$ Professora do Curso de Engenharia Ambiental da Universidade Federal do Amazonas, UFAM - Humaitá \\ e-mail: klenna.star@gmail.com \\ ${ }^{2}$ Técnica do Laboratório de Saneamento da UFAM - Humaitá e-mail: harumynoguchi@ hotmail.com \\ ${ }^{3}$ Engenheira Ambiental pela UFAM - Humaitá - e-mail: annerelvas@gmail.com \\ ${ }^{4,5}$ Professores do Departamento de Engenharia Sanitária e Ambiental da Universidade Federal de Mato Grosso - UFMT \\ e-mail: marchetto.ro@gmail.com e e-mail: aldecy allmmeida@yahoo.com.br
}

Enviado em maio 2014: Aceito em junho $2014 \quad$ Publicado em Novembro 2014

Resumo: O rio Beem localiza-se no Estado do Amazonas, na região Norte do Brasil, está inserido na bacia hidrográfica do Rio Madeira, no município de Humaitá. As águas desse rio são destinadas para usos múltiplos, como: balneabilidade, paisagismo, pesca ou mesmo para a realização de atividades inerentes à sobrevivência humana, bem como dessedentação de animais e irrigação em pequenas propriedades. O presente trabalho teve como objetivo avaliar as características quali-quantitativas do Rio Beem, para subsidiar informações para gestão e planejamento dos recursos hídricos da bacia. Foram realizados parâmetros físicos, químicos e bacteriológicos das águas a montante, jusante e no perímetro urbano da cidade de Humaitá-AM. Paralelamente, foi determinada a vazão a montante e jusante da área em estudo no período de cheia e vazante, utilizando o método do flutuador, por fim, foi determinado Índice de Qualidade da Água. Mediante os resultados obtidos por meio do monitoramento, as análises dos parâmetros $\mathrm{DBO}_{5}$, OD, Fósforo Total, $\mathrm{pH}$ e Óleos e Graxas, apresentaram de acordo com a Resolução $n^{\circ}$ 357/05 do Conselho Nacional do Meio Ambiente, para rios de classe 2. Os resultados de turbidez mantiveram-se em geral inferiores ao limite máximo indicado pela legislação vigente: 100 NTU. As concentrações de coliformes Escherichia Coli apresentaram-se valores superiores ao limite de 1000 NMP/100mL permitido pela Resolução CONAMA n³75/05 nos pontos PB4 e PB3 no mês de agosto de 2010, e nos meses de abril e junho de 2011. As maiores concentrações de coliforme totais foram no período de cheia, no mês de agosto de 2011. As vazões a montante e jusante da cidade de Humaitá-AM, mantiveram-se maiores no período de cheia por causa do aumento da precipitação na bacia. O Índice de Qualidade da Água foi classificado como ótimo e bom, para os períodos de cheia e vazante, respectivamente.

Palavras-chave: Recurso hídrico, Bacia hidrográfica, Método flutuador.

\begin{abstract}
The Beem River is located in Amazonas state, in the northern Brazil, is inserted in the basin of the Madeira River, in the Humaitá municipality. The waters of this river are used for various purposes such as: bathing, landscaping, fishing or even to carry out activities related to human survival, as well as irrigation and watering livestock on small farms. This study aimed to assess the qualitative and quantitative characteristics of Beem River, to support information for management and planning of water resources of the basin. Parameters Physical, chemical and bacteriological water upstream and downstream in the city limits of Humaitá-AM were performed. In parallel, the upstream and downstream flow of the study area during the flooding and ebbing was determined using the method of the float finally was given the Water Quality Index. From the results obtained by monitoring, analyzes of BOD5, DO, total phosphorus, $\mathrm{pH}$ and Oils and Greases parameters, presented in accordance with Resolution No. 357/05 the National Environmental Council for rivers class 2. Results of turbidity remained generally below the thresholds set by law: 100 NTU. Concentrations of Coliforms Escherichia coli showed up to the upper limit of $1000 \mathrm{MPN} / 100 \mathrm{~mL}$ allowed by CONAMA Resolution 375/05 in points PB4 and PB3 , in August 2010, and in April and June 2011. The highest concentrations values of total coliform were in the rainy season, in August 2011. Flows upstream and downstream from Humaita-AM, remained higher during the flooding because of increased rainfall in the basin. The Water Quality Index was classified as excellent and good, for the periods of flood and drought, respectively.
\end{abstract}

Keywords: Water resource, Watershed, float method 


\section{Introdução}

Devido ao grande crescimento demográfico e das atividades econômicas por parte da sociedade, aumentaram-se o consumo dos recursos primários, principalmente dos recursos hídricos. Este consumo gera um grande impacto na quantidade e qualidade da água, causando muitas vezes a sua deterioração, o que ameaça a sobrevivência humana e das demais espécies do planeta (BORGES et al., 2003).

A água é fonte indispensável de vida, uma vez que atende múltiplas necessidades e interesses das populações, como a manutenção da saúde pública, desenvolvimento econômico, recreação e a preservação do equilíbrio ecológico. Benetti et al. (2003). Faz-se necessário o equilíbrio entre a utilização da água e a manutenção da sua condição natural dos corpos hídricos permitindo o uso continuado. Porém, quando este equilíbrio não é imposto, o atendimento aos interesses humanos é afetado, trazendo enormes prejuízos à sociedade.

Diante desta problemática, surge outra discussão sobre a utilização das águas, em especial daqueles corpos hídricos, cujos cursos atravessam as áreas urbanas. Este cenário tem se tornado um risco à saúde de seus usuários que por falta de informações e acompanhamento por parte das autoridades competentes continuam se banhando, bebendo, e lavando roupas e louças nestas águas. Isto é mais preocupante nos bairros localizados nas periferias, onde geralmente, não existe rede de água e de efluentes domésticos, ou seja, os meios mínimos necessários para que a população tenha uma qualidade de vida razoável (OTTONELLI, 2005).

O Rio Beem localiza-se no município de Humaitá no Estado do Amazonas e tem grande influência das atividades antrópicas. A população usa suas águas para fins de balneabilidade, paisagismo, navegação, pesca ou mesmo para a realização de atividades inerentes a sobrevivência humana, entre outras.

Por esta problemática, o objetivo deste trabalho é avaliar a qualidade e quantidade da água do Rio Beem no Município de Humaitá-AM, visando subsidiar a gestão adequada dos recursos hídricos.

\section{Materiais e Métodos}

A bacia hidrográfica do Rio Beem está inserida na bacia do Rio Madeira, pertencente a Região Hidrográfica do Amazonas, localizada no estado do Amazonas, na região Norte do Brasil, abrange o município de Humaitá como demonstrado na Figura 1.

A bacia do Rio Beem está situada na mesma zona climática, segundo Köppen, pertencendo ao grupo A (Clima Tropical Chuvoso) e tipo climático Am (chuvas do tipo monção), apresentando um período seco de pequena duração. As temperaturas médias anuais variam entre $25^{\circ} \mathrm{C}$ e $27^{\circ} \mathrm{C}$ e a umidade relativa do ar entre 85 e $90 \%$.

\section{Descrição da Metodologia}

Para a avaliação da qualidade e quantidade da água do Rio Beem, primeiramente, foi realizada a descrição dos pontos de coleta. Paralelamente a determinação da qualidade da água, as medições de vazão foram realizadas a montante e jusante da área em estudo no período de cheia e vazante, utilizando o método do flutuador, por fim, o índice de qualidade da água. Os pontos selecionados para a coleta da água do Rio Beem foram selecionados de acordo com os seguintes critérios: áreas de ocupação e distanciamento do meio urbano. Os pontos estão assim localizados (Tabela 1). 
Figura 1 - Localização da área de estudo no Rio Beem.

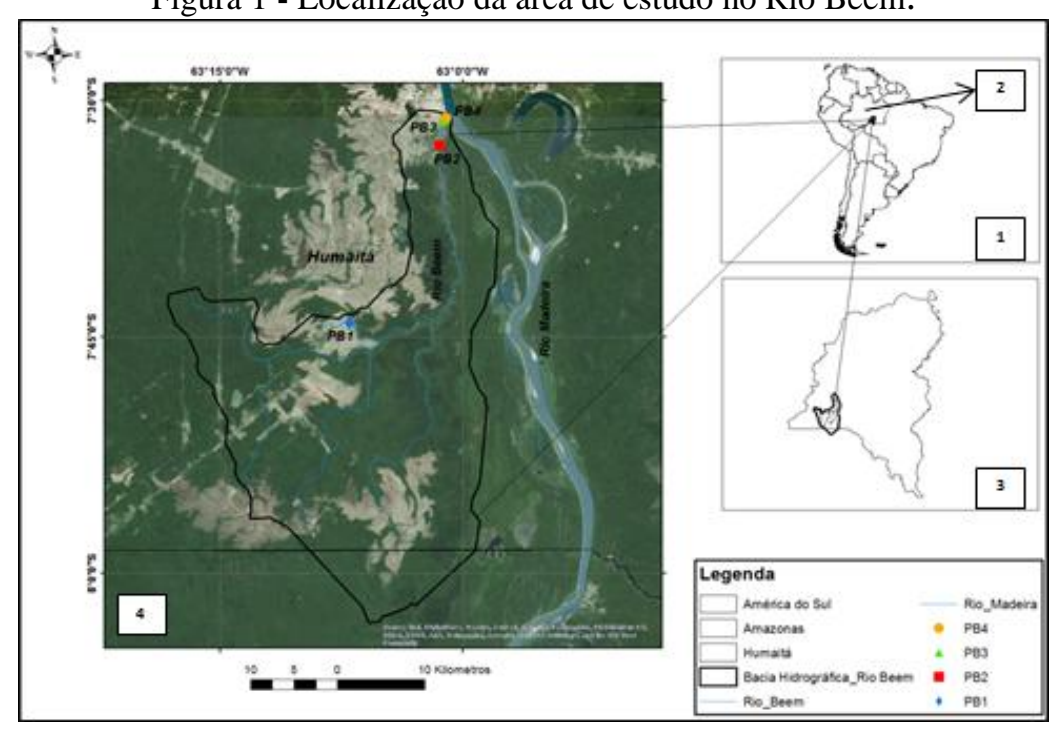

Fonte: (SANTOS; Aldecy de Almeida)

Tabela 1. Coordenadas dos pontos de coleta do Rio Beem.

\begin{tabular}{|c|c|}
\hline Código dos pontos de coleta & Coordenadas Geográfica \\
\hline PB1 & 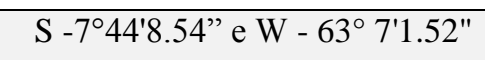 \\
\hline PB2 & $\mathrm{S}-7^{\circ} 32^{\prime} 52.43^{\prime \prime}$ e W - $63^{\circ} 1 ' 22.09^{\prime}$ \\
\hline PB3 & S - $7^{\circ} 31^{\prime} 19.75^{\prime \prime}$ e W - 631'7.74" \\
\hline PB4 & S - $7^{\circ} 31^{\prime} 7.41^{\prime \prime}$ e W $-63^{\circ} 1^{\prime} 0.21^{\prime \prime}$ \\
\hline
\end{tabular}

As amostras coletadas foram armazenadas em frascos de polietileno de $500 \mathrm{ml}$, sendo conservadas em temperatura de $4^{\circ} \mathrm{C}$ e medidas com termômetro até a fase de análises em laboratório. As análises foram feitas nos laboratórios: Laboratório de Saneamento da Universidade Federal do Amazonas (UFAM), Laboratório de Análises Físico-Química da Água da Universidade Federal de Mato Grosso (UFMT) e Laboratório Analítica. Os parâmetros físico-químicos, bem como os exames bacteriológicos de coliformes totais e termotolerantes, foram analisados conforme (APHA et al., 1995), como apresentado na Tabela 2. Para subsidiar a quantidade da água, fez-se a determinação da vazão, sendo realizadas medições nos períodos de agosto de 2010 a julho de 2011. Essas foram realizadas na montante e jusante da área em estudo no Rio Beem, nos períodos de cheia e vazante, utilizando o método do flutuador.

Para a caracterização do Índice de Qualidade da Água, foram utilizados alguns parâmetros que representam suas características físico-químicas e bacteriológicas. Estes parâmetros foram estabelecidos pela National Sanitation Foudantion (NSF) nos Estados Unidos. Desse modo, nove parâmetros foram considerados mais representativos: oxigênio dissolvido, coliformes termotolerantes, $\quad \mathrm{pH}, \quad$ demanda bioquímica de oxigênio, nitrato, fosfato total, temperatura da água, turbidez e sólidos totais. Para cada parâmetro, foi possível traçar curvas médias da variação da qualidade da água em função das suas respectivas concentrações. A cada parâmetro atribuiu-se um peso, listados na Tabela 3, de acordo com sua importância relativa no cálculo do IQA/NSF 
Peixoto K. L. G., Noguchi H. S., Pereira A. R., Marchetto M., Santos A. A., Avaliação das Características Quali-Quantitativas das Águas do Rio Beem. Município de Humaitá-Amazonas. E\&S - Engineering and Science, (2014), 2:1.

Tabela 2 - Metodologias empregadas nas análises da água do Rio Beem Fonte: APHA (1992).

\begin{tabular}{lll}
\hline \multicolumn{1}{c}{ Parâmetros } & \multicolumn{1}{c}{ Metodologia } & \multicolumn{1}{c}{ Equipamentos } \\
\hline DBO $_{\mathbf{5}}$ & Iodométrico & Incubadora Marca Velpe \\
Nitrogênio Total & Semi-microKjedahl & Destilador de Nitrogênio BT 541 \\
pH & Potenciométrico & pHmeter Tec-2 Marca Tecnal \\
Fósforo & Ácido ascórbico & Digestor VELPE ECO 8 \\
Cor & Colorimétrico & HI 83200 BENCH \\
Turbidez & Turbidimetro & HI 88703 - HANNA \\
Coliformes Totais & Colilert & Colilert \\
Óleos e Graxa & Espectrometria & Analisador infracal TOG/THP \\
Oxigênio Dissolvido & Iodométrico & volumetria de óxido-redução \\
E. Coli & Colilert & Colilert \\
Nitrato & Espectrofotometria & Espectrofotômetro \\
Fosfato & Espectrofotometria & Espectrofotômetro \\
Resíduo Total & Gravimétrico & Estufa \\
Temperatura & Termômetro & Termômetro \\
\hline
\end{tabular}

Tabela 3 - Parâmetros e pesos do IQA Fonte: CETESB (2007).

\begin{tabular}{cccc}
\hline Parâmetros & Pesos & Parâmetros & Pesos \\
\hline OD & 0,17 & Nitrogênio Total & 0,10 \\
DBO $_{5}$ & 0,10 & Fósforo & 0,10 \\
Coliformes Termotolerantes & 0,15 & Resíduos Totais & 0,08 \\
Temperatura & 0,10 & Turbidez & 0,08 \\
pH & 0,12 & & \\
\hline
\end{tabular}

O IQA é calculado pelo produtório ponderado das qualidades de água correspondentes aos parâmetros, conforme a fórmula:

Onde:

$$
I Q A=\prod_{i=0}^{9} q_{i}^{w i}
$$

IQA - índice de qualidade da água, um número de 0 a 100

qi = qualidade do parâmetro i obtido através da média de qualidade; wi $=$ peso atribuído ao parâmetro, em função de sua importância na qualidade, entre 0 e 1 .

Os valores do índice variam entre 0 e 100, conforme especificado na Tabela 4

Tabela 4 - Nível de qualidade do IQA.

\begin{tabular}{lccc}
\hline \multicolumn{1}{c}{ Descrição (NSF) } & FAIXA & Descrição (CETESB) & FAIXA \\
\hline Péssima qualidade & $0-25$ & Péssima & $0-19$ \\
Má qualidade & $20-36$ & Ruim & $20-36$ \\
Média qualidade & $37-51$ & Regular & $37-51$ \\
Boa qualidade & $52-79$ & Boa & $52-79$ \\
Excelente qualidade & $91-100$ & Ótima & $80-100$ \\
\hline
\end{tabular}

Fonte: CETESB (2007) 
Peixoto K. L. G., Noguchi H. S., Pereira A. R., Marchetto M., Santos A. A., Avaliação das Características Quali-Quantitativas das Águas do Rio Beem. Município de Humaitá-Amazonas. E\&S - Engineering and Science, (2014), 2:1.

\section{Resultados e Discussões}

Conforme a resolução do CONAMA $\mathrm{n}^{\circ}$ $357 / 2005$, o rio Beem classifica-se como rio de águas doces de classe II devido ao uso de sua água ser destinada ao abastecimento para consumo humano, após tratamento convencional, à proteção das comunidades aquáticas e recreação de contato primário, tais como natação, esqui aquático e mergulho.

\section{Parâmetros Físicos}

Cor

Conforme a Figura 2, as maiores concentrações de cor do Rio Beem ocorreram no período chuvoso, com valor máximo no PMB2, este fato se origina através dos sólidos dissolvidos e decomposição da matéria orgânica na água.

Figura 2 - Resultados de Cor.

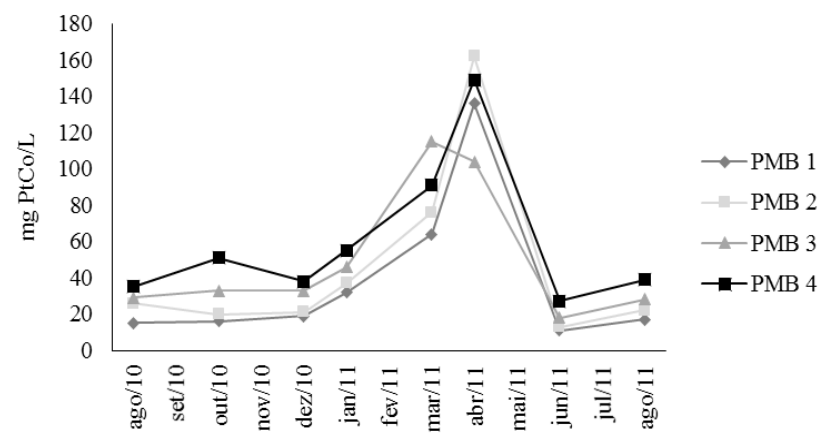

Os meses de março e abril apresentaram concentrações de cor superior a 75 $\mathrm{mgPt} / \mathrm{L}$, não estando de acordo com o valor estipulado pela Resolução CONAMA $n^{\circ}$ 357/05. Provavelmente a origem esta relacionada a decomposição da matéria orgânica antrópicas como lixiviação de vias urbanas e descargas de efluentes domésticos ou industriais.

\section{Turbidez}

Os valores de Turbidez encontrados foram maiores no período de estiagem (Figura 3). Essa elevação ocorre devido ao arraste

de sólidos da área de drenagem e da argila da Margem do Rio Beem. Os valores de turbidez diminuíram no período chuvoso por causa do aumento do volume da água, ocasionando à diminuição da velocidade e da turbulência dentro da área molhada, contribuindo para a redução da suspensão de sólidos do fundo e da margem do Rio. Os esultados de turbidez obtidos nas amostras da água do Rio Beem mantiveram-se, abaixo do limite máximo indicado pela legislação vigente (100 NTU) exceto os PMB3 e PMB4 referente os meses de agosto e outubro de 2010 e junho de 2011.

Figura 3 Resultados de Turbidez

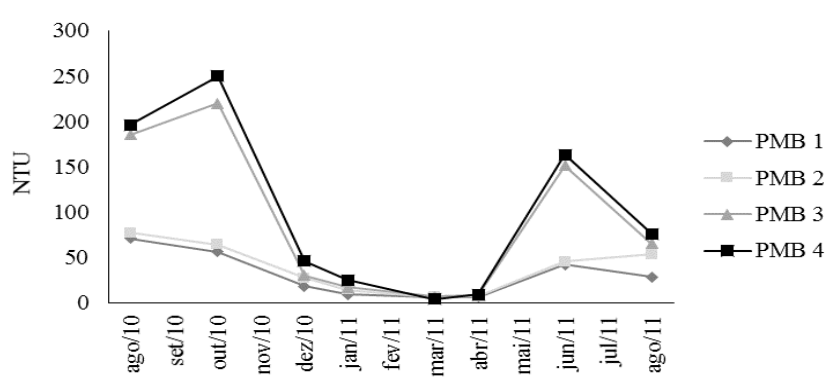


Peixoto K. L. G., Noguchi H. S., Pereira A. R., Marchetto M., Santos A. A., Avaliação das Características Quali-Quantitativas das Águas do Rio Beem. Município de Humaitá-Amazonas. E\&S - Engineering and Science, (2014), 2:1.

\section{Temperatura}

A temperatura da água do Rio Beem apresentou valores entre $25^{\circ} \mathrm{C}$ a $29^{\circ} \mathrm{C}$ no período de cheia e vazante, respectivamente, estando inferior a 40 ${ }^{\circ} \mathrm{C}$ da Resolução do CONAMA nº 357.

\section{Parâmetros Químicos}

\section{Demanda Bioquímica de Oxigênio $\left(\mathrm{DBO}_{5}\right)$}

A concentração de $\mathrm{DBO}_{5}$ apresentou valores superiores no período de cheia conforme Figura 4. Esse acréscimo no período de cheia ocorre devido ao transporte de solo e resíduos orgânicos de origem vegetal para os corpos hídricos.

Os dados também indicaram no período de estudo o aumento da $\mathrm{DBO}_{5}$ da montante do Ponto PMB1 para o Ponto a jusante PMB 4.
$\mathrm{Na}$ Figura 4, verifica-se que os resultados de $\left(\mathrm{DBO}_{5}\right)$ do mês janeiro, março e junho de 2011 nos pontos PMB3 e PMB4 apresentaram concentrações mais elevadas, provavelmente devido ao lançamento de esgoto sem tratamento das residências da área urbana de Humaitá no Rio Beem.

As concentrações de $\mathrm{DBO}_{5}$ no período de estudo estão dentro do limite estabelecido pela Resolução $\mathrm{n}^{\circ}$ $357 / 2005$ do CONAMA para corpos d'água de classe 2 .

3.3.2. Oxigênio Dissolvido (OD)

De acordo com a Figura 5, verifica-se que as concentrações de OD foram maiores no período chuvoso, devido ao aumento da vazão do curso d'água do Rio Beem. Segundo O’Connor (1967) a presença de altas concentrações de OD indicam que não há presença de matéria orgânica.

Figura 4 - Demanda Bioquímica de Oxigênio $\left(\mathrm{DBO}_{5}\right)$.

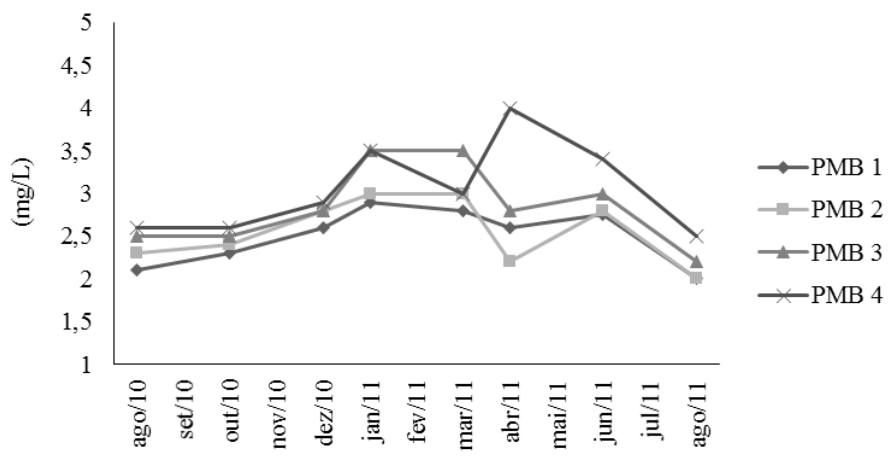

Figura 5 - Oxigênio Dissolvido.

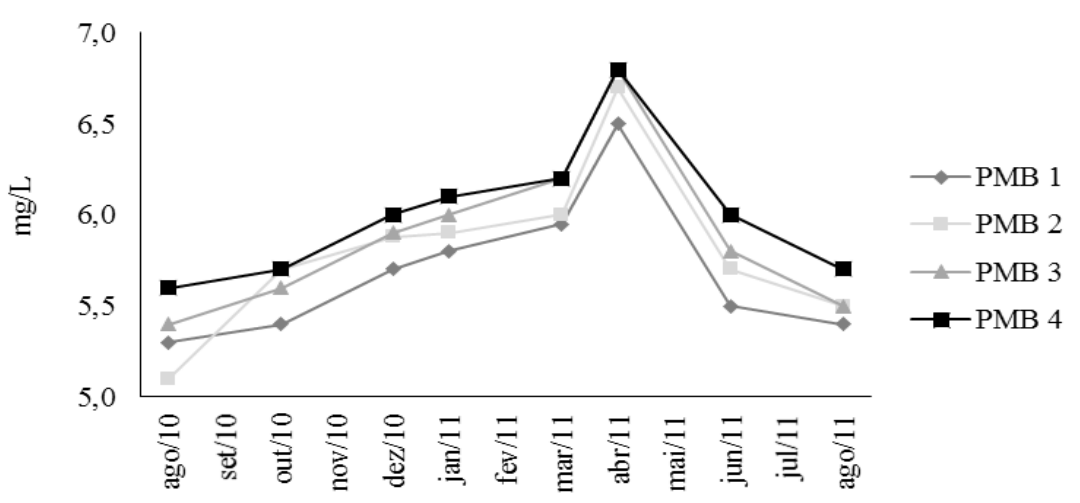


Peixoto K. L. G., Noguchi H. S., Pereira A. R., Marchetto M., Santos A. A., Avaliação das Características Quali-Quantitativas das Águas do Rio Beem. Município de Humaitá-Amazonas. E\&S - Engineering and Science, (2014), 2:1.

O oxigênio dissolvido foi aumentando da montante para a jusante devido o aumento de nível do rio período chuvoso contribuindo com a melhoria dos níveis de oxigênio dissolvido.

$\mathrm{Na}$ análise efetuada verificou-se que as concentrações de OD mantiveram-se dentro do padrão legal estabelecido pela
Resolução CONAMA nº 357/05 com valores não inferiores a $5 \mathrm{mg} / \mathrm{L}$.

\section{Nitrogênio Total}

Para o parâmetro de nitrogênio total, temos valores apenas no período chuvoso, no qual os maiores valores foram no PB 3 e PB 4 (Figura 6).

Figura 6. Nitrogênio total.

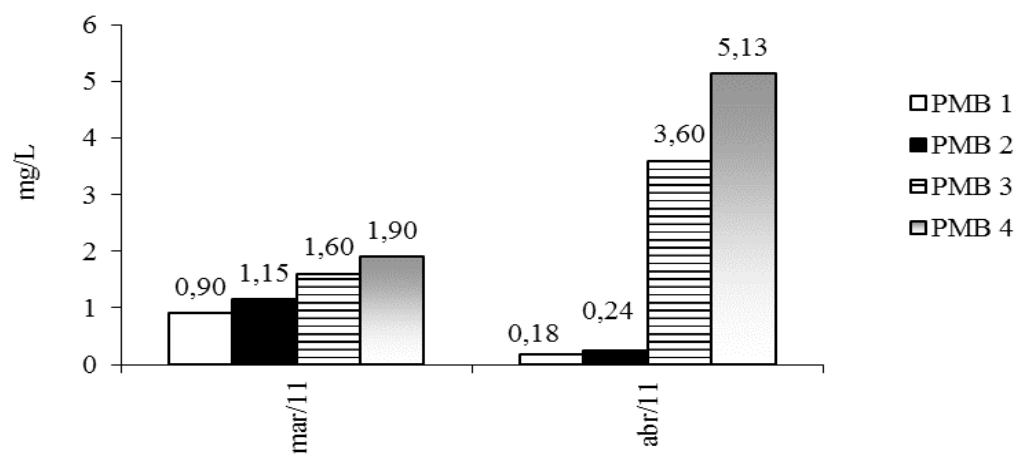

Para o crescimento de algas o parâmetro nitrogênio é um elemento indispensável, porém em elevadas concentrações, pode provocar o crescimento exagerado das algas, ocasionando a eutrofização (LIMBERGER et al., 2005).

\section{Nitrato}

A maior concentração de nitrato foi no PB4 no período de cheia (Figura 7) e a menor concentração no PB1. Esta concentração aumenta do PB1 montante para jusante

Figura 7 - Nitrato

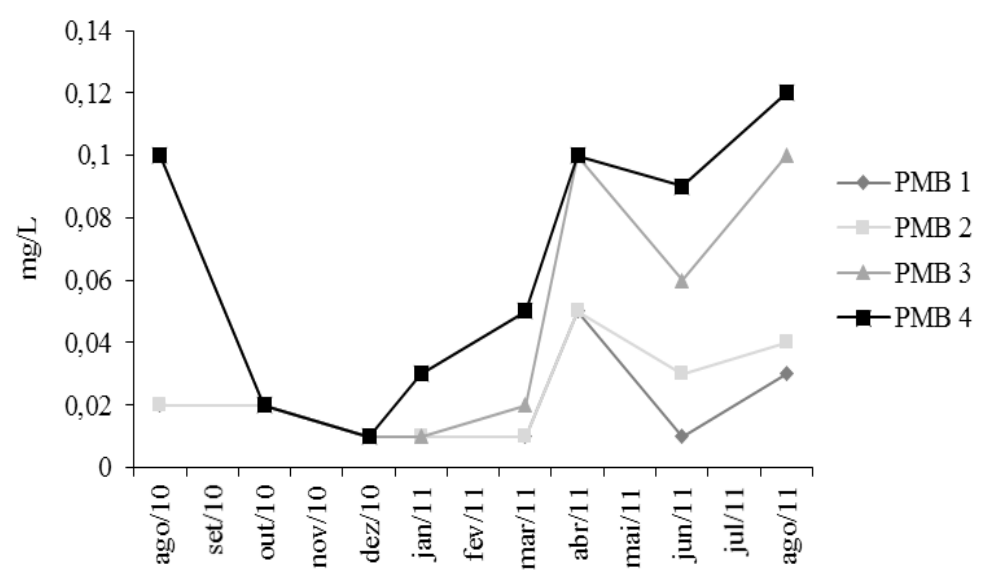


A produção do nitrato resulta da oxidação bacteriana do amônio, tendo o nitrito como intermediário (BAUMGARTEN E POZZA, 2001).

\section{Fósforo Total}

Encontrou-se a maior concentração de fósforo total no PMB 3, mês de março como apresentado na Figura 8. Essa concentração de fósforo próximo ao perímetro urbano da cidade de Humaitá, provavelmente, deve-se à matéria orgânica lançada por esgoto doméstico sem tratamento. $\mathrm{O}$ fósforo total é originado naturalmente da dissolução de compostos do solo e da decomposição da matéria orgânica

Figura 8 - Resultados de Fósforo

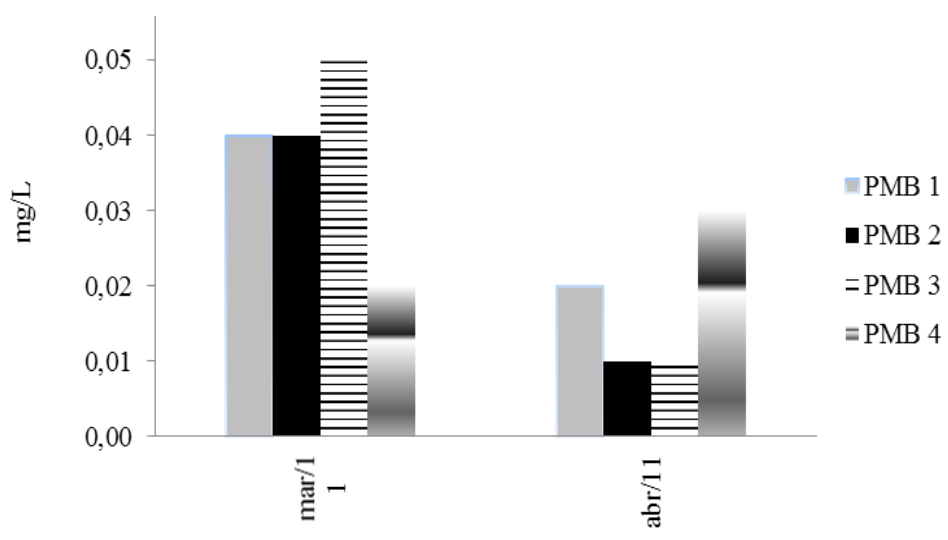

Os resultados de concentração de fósforo total obtidos encontram-se de acordo com valor máximo permitido pela resolução do Conama n ${ }^{\circ} 357 / 05$, apresentando valores inferiores a $0,1 \mathrm{mg} / \mathrm{L}$.

\section{Fosfato Total}

Conforme a Figura 9, o maior valor de concentração de fosfato total no estudo foi no período chuvoso no PB 3.

Os menores valores de fosfato total foram nos PMB 1 e PMB 2 no período vazante.De acordo com Baumgarten et al. (1996), o lançamento de efluentes com grandes concentrações de fosfatos em cursos d'água pode, em ambientes com boa disponibilidade de nutrientes nitrogenados, estimular o crescimento de micro e macroorganismos fotossintetizadores.

\section{Potencial hidrogeniônico $(p H)$}

De acordo com os resultados, os maiores valores de $\mathrm{pH}$ encontrado foram no período de vazante nos meses de outubro, dezembro de 2010 e agosto 2011(Figura 10).

Valores altos de $\mathrm{pH}$ (alcalino) de sistemas hídricos podem estar associados à proliferação de vegetais em geral, pois com o aumento da fotossíntese há consumo de gás carbônico e, portanto, diminuição do ácido carbônico da água e consequente aumento do $\mathrm{pH}$ (VON SPERLING, 1995). Os valores de $\mathrm{pH}$ nos quatros pontos de coleta estão dentro dos limites estabelecidos pela Resolução CONAMA $n^{\circ} 357$, no qual o Rio Bem e classificado como rio de água doce de classe 2. 
Peixoto K. L. G., Noguchi H. S., Pereira A. R., Marchetto M., Santos A. A., Avaliação das Características Quali-Quantitativas das Águas do Rio Beem. Município de Humaitá-Amazonas. E\&S - Engineering and Science, (2014), 2:1.

Figura 9 - Resultados de Fosfato total

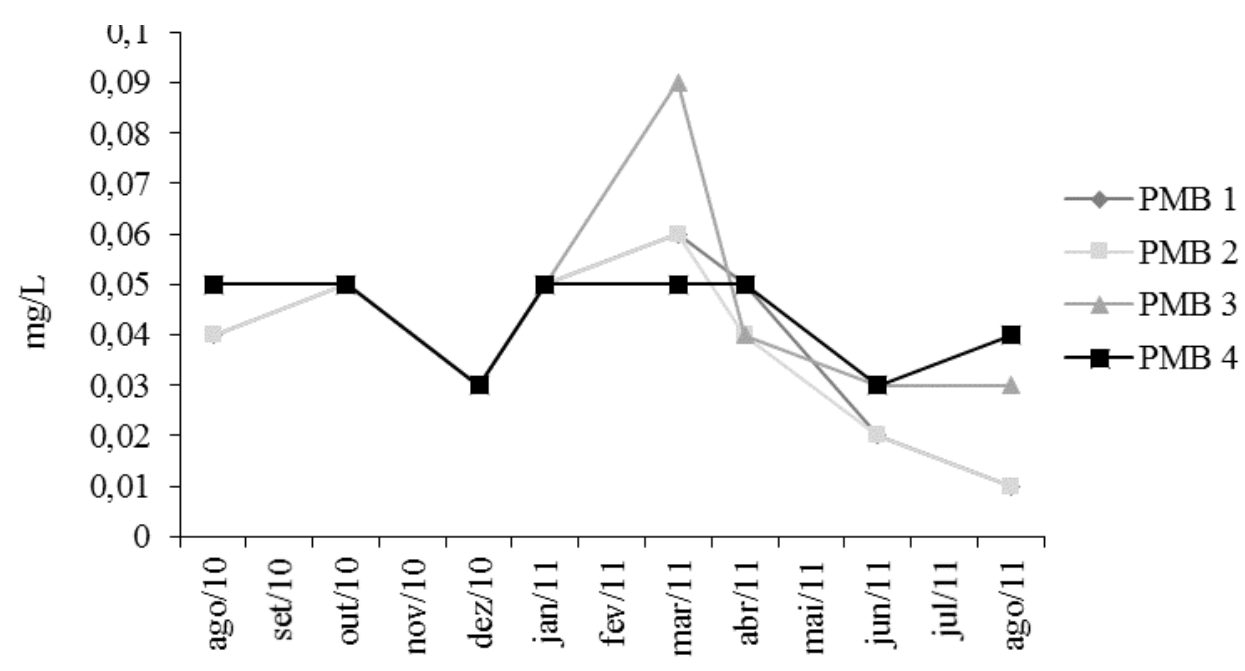

Figura 10- Resultados de pH

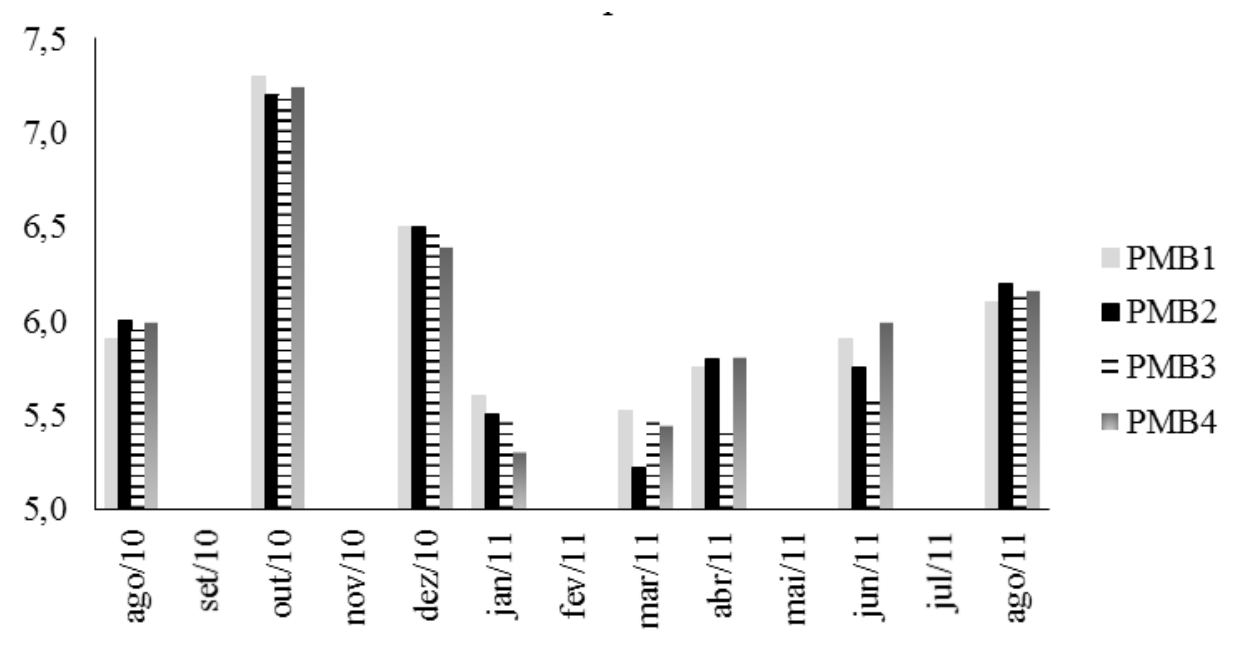

Óleos e Graxas

Conforme exposto na Figura 11, as maiores concentrações de óleos e graxas foram no PB3 no mês de março de 2011.

Presença de óleos lubrificantes, graxas, hidrocarbonetos, ácidos graxos, sabões, gorduras, óleos e ceras, assim como alguns compostos de enxofre, certos corantes orgânicos e clorofila (BAUMGARTEN E POZZA, 2001). Em todos os pontos de coleta tanto no período de cheia e vazante os valores encontrados estão de acordo com a Resolução do CONAMA 357/05 virtualmente ausente. 
Peixoto K. L. G., Noguchi H. S., Pereira A. R., Marchetto M., Santos A. A., Avaliação das Características Quali-Quantitativas das Águas do Rio Beem. Município de Humaitá-Amazonas. E\&S - Engineering and Science, (2014), 2:1.

Figura 11 - Óleos e Graxas

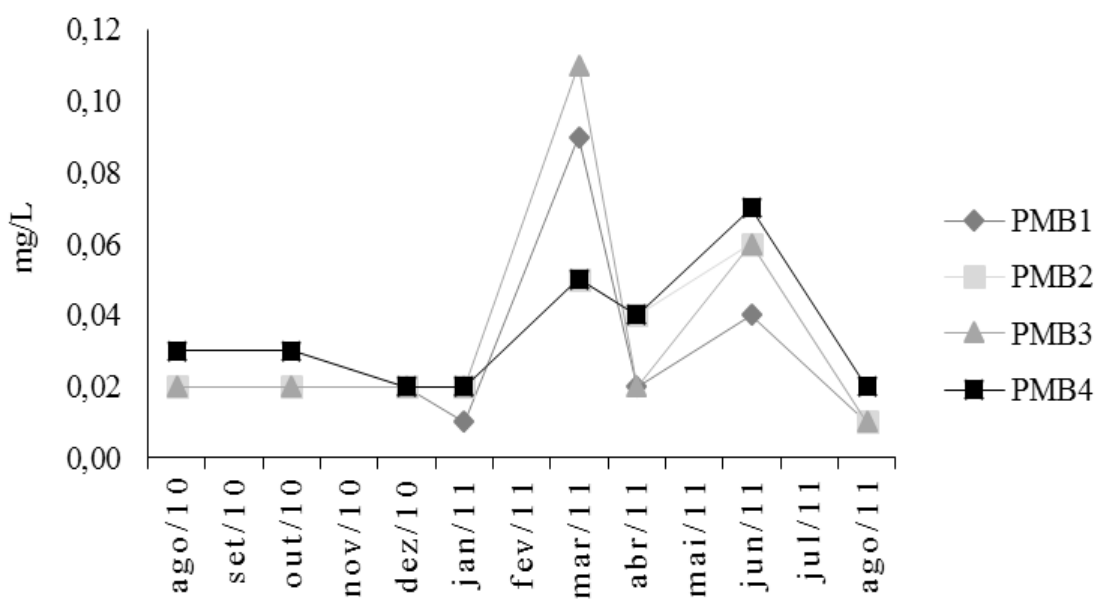

Resíduo Total

No período de seca o resultado de resíduo total encontrado foi de $33 \mathrm{mg} / \mathrm{L}$ e no período de cheia $1330 \mathrm{mg} / \mathrm{L}$

\section{Parâmetros Bacteriológicos}

\section{Coliformes Termotolerantes}

Conforme a Figura 12, os resultados da concentração de coliformes E. Coli estão superior ao limite permitido de 1000 NMP/100Ml permitido pela Resolução CONAMA n $375 / 05$ nos pontos PB 4 e PB3 entre 2010 e 2011 do mês de agosto e no ano de 2011 entre os meses de abril e junho, provavelmente, devido à pouca vazão do Rio Beem fazendo com que ocorra uma menor diluição do lançamento de esgoto bruto ou dejetos animais

Figura 12 - Escherichia Coli

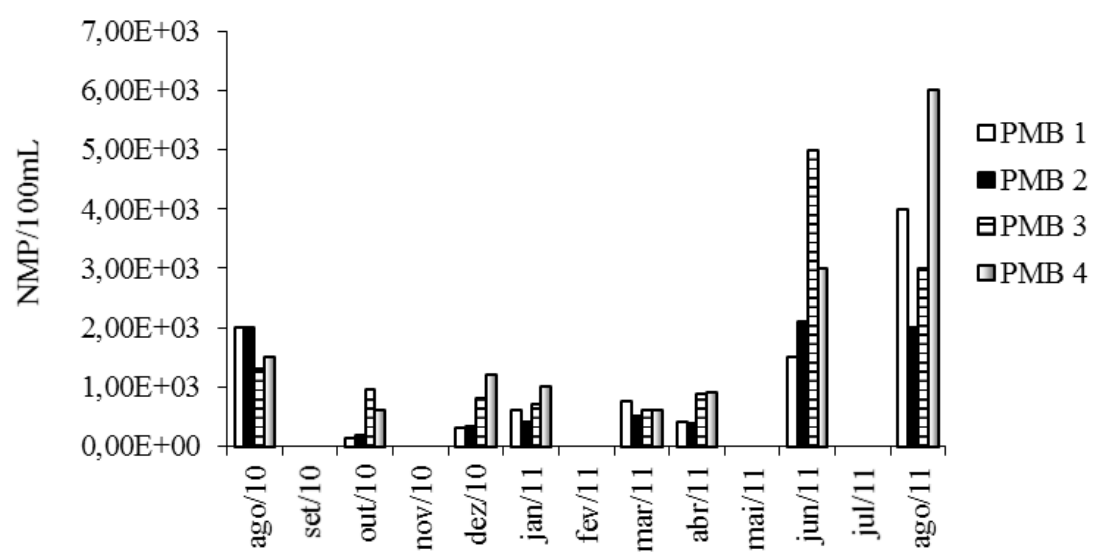

\section{Coliformes Totais}

As concentrações de coliforme totais (Figura 13) mostram que os maiores valores foram no mês de agosto de 2011 no período de cheia. Provavelmente devido ao lançamento de esgoto bruto. 
Peixoto K. L. G., Noguchi H. S., Pereira A. R., Marchetto M., Santos A. A., Avaliação das Características Quali-Quantitativas das Águas do Rio Beem. Município de Humaitá-Amazonas. E\&S - Engineering and Science, (2014), 2:1.

Figura 13 - Coliformes totais

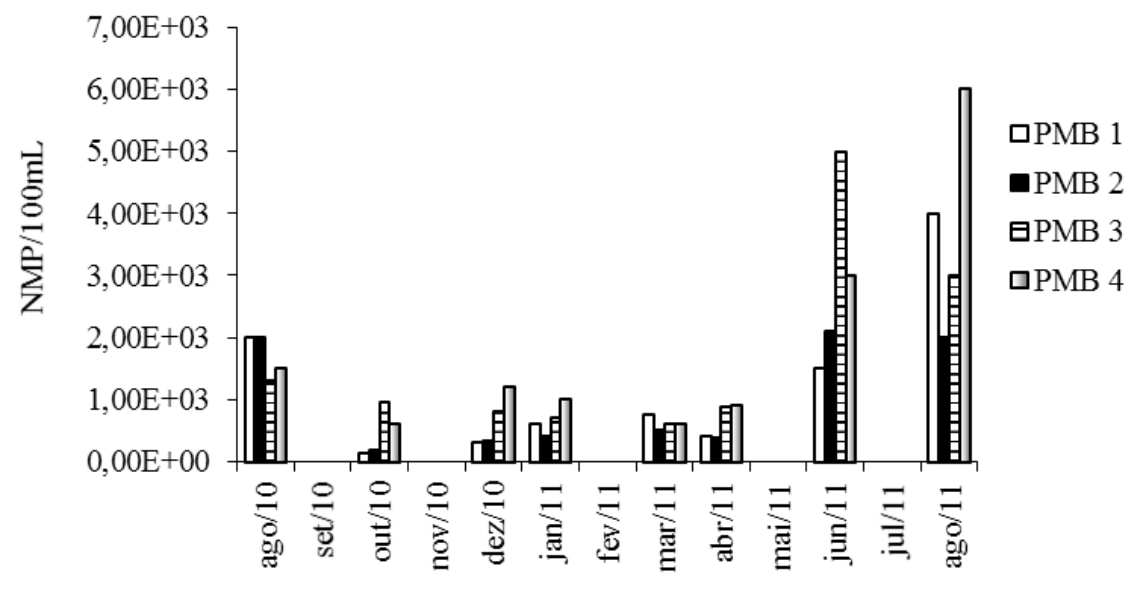

A determinação da concentração dos coliformes assume importância como parâmetro indicador da possibilidade da existência de microorganismos patogênicos.

\section{IQA - Índice De Qualidade Da Água}

O Índice de Qualidade da Água dos pontos PMB1, PMB2, PMB3 e PMB4 no período de cheia apresentaram valores na faixa de 80 - 100, respectivamente, considerados como ótimos. No período de vazante os quatro pontos estudados indicaram valores entre a faixa de $52-72$ considerando a sua descrição como boa. A mudança na descrição da qualidade da água de ótima para boa ocorre devido à influência dos sólidos totais e coliformes termotolerantes, pois no período de vazante a vazão do Rio Beem é menor fazendo com que estes não sejam diluídos como no período de cheia.

\section{Caracterização Hidráulica}

Os resultados da variação das vazões, durante o período de estudo da bacia do rio Beem entre o período de cheia e vazante, serão apresentados neste subcapítulo.

\section{Vazão Montante e Jusante do Rio Beem}

Observa-se que a montante (PMB1) e a jusante (PMB4) do Rio Beem (Figura 14) apresentam o maior volume de água no período de cheia.

Figura 14 - Vazão período de cheia a montante (PB1) e jusante (PB4).

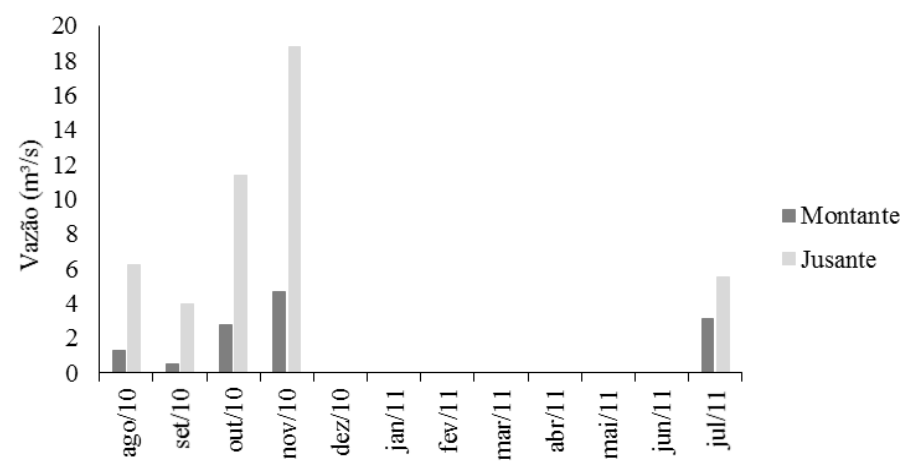


Os valores de vazão no período de vazante (Figura 15) na montante (PMB1) e na jusante (PMB4) foram no mês de novembro de 2010.

Com a análise dos dados de vazão notou-se que o aumento da vazão ocorre da montante para a jusante.
Ressalta-se também que os maiores valores de vazão encontrados foram no período de cheia devido ao aumento da precipitação na bacia e a contribuição do rio Caxirí, que deságua no rio Beem

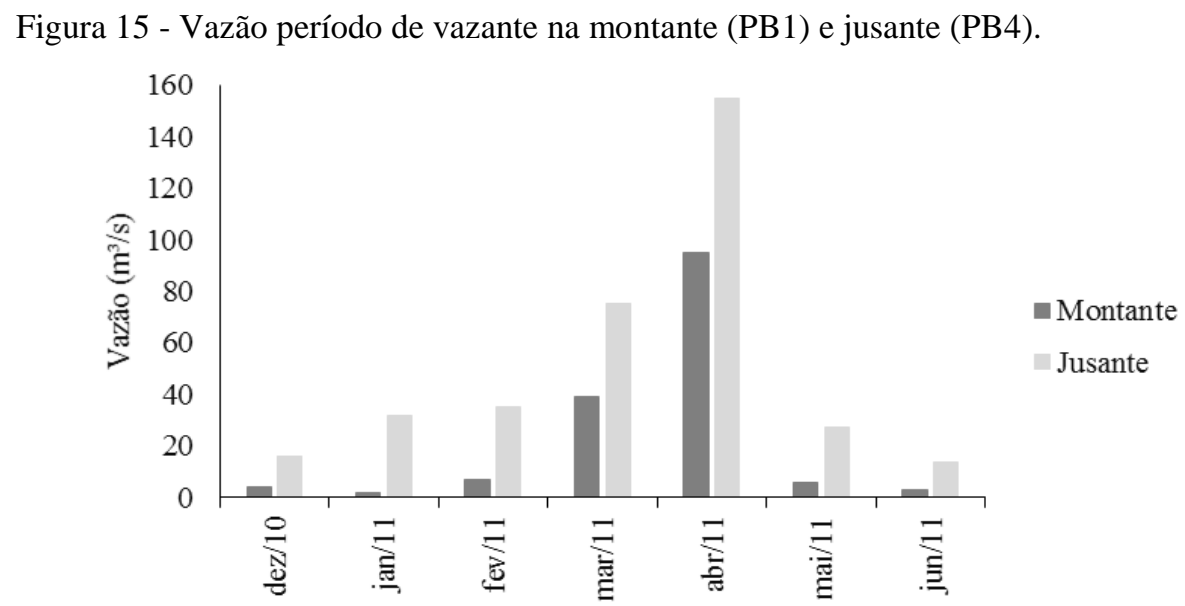

\section{Conclusão}

Mediante os valores encontrados através das análises dos parâmetros $\mathrm{DBO}_{5}, \mathrm{OD}$, Fósforo Total, pH e Óleos e Graxas concluímos que estes se encontram de acordo com os valores máximos permitidos pela Resolução do CONAMA 357/05 para rios de água doce de classe 2 . Os resultados de Cor nos meses de março e abril de 2011 apresentaram concentrações superiores a $75 \mathrm{mgPt} / \mathrm{L}$. Os resultados de turbidez mantiveram-se abaixo do limite máximo indicado pela legislação vigente (100 UNT) exceto o PMB3 e PMB4 nos meses de agosto e outubro de 2010 e junho de 2011.

As concentrações de coliformes E. Coli apresentam valores superiores ao limite de $1000 \mathrm{NMP} / 100 \mathrm{~mL}$ permitido pela Resolução CONAMA n³75/05 nos pontos PMB 4 e PMB3 para o mês de agosto 2010 e entre os meses de abril e junho ano de 2011. Provavelmente isto ocorre devido à pouca vazão do Rio Beem fazendo com que ocorra menor diluição do lançamento de esgoto bruto ou dejetos animais. De acordo os resultados bacteriológicos o Rio Beem necessita de tratamento convencional, com cuidados especiais de desinfecção para ser utilizado para abastecimento público.

O Índice de Qualidade da Água (IQA) revelou qualidade como ótima no período de cheia e uma redução da classificação da qualidade para boa devido a influência dos sólidos totais e coliformes Termotolerantes.

No mês de abril, a vazão do Rio Beem apresentou o maior valor, a montante e jusante da cidade. Observou-se também que o aumento da vazão ocorre da montante para a jusante.

\section{Referências}

APHA, AWWA, WPCFC. Standard Methods for the Examination of Water, 1992; and ARAÚJO, J. C. SANTAELLA, S. T. Gestapo da Qualidade. Porto Alegre, RS: ABRH. $2^{\text {a }}$ ed. 242 p. 2001.

BAUMGARTEN, M. G. Z.; POZZA, S. A. Qualidade de Águas. Descrição de Parâmetros Químicos referidos na 
Legislação Ambiental. Rio Grande: Munícipio de Frederico Westphalen, Editora da FURG, 166p, 2001.

BAUMGARTEN, M. G. Z.; ROCHA, J. M. B.; NIENCHESKI, L. F. H. Manual de Análises de Oceanografia Química. Rio Grande: Editora da FURG, 132 p, 1996.

BENETTI, A. D.; LANNA, A. E.; COBALCHINI, M. S. Metodologias para determinação de vazões ecológicas em rios. Revista Brasileira de Recursos RS, a Partir do Estudo de Diatomáceas. Frederico Westphalen, 2005. Monografia de Conclusão de Curso, Departamento de Ciências Biológicas. Frederico Westphalen, 2005.

VON SPERLING, M. V. Princípio do tratamento biológico de águas residuárias. IN: Introdução à qualidade das águas e ao tratamento de esgotos, 1995.

Hídricos, Porto Alegre, v. 8, 2003.

BORGES, M. J.; GALBIATTI, J. A.; FERRAUDO, A. S. Monitoramento da qualidade hídrica e eficiência de interceptores de esgoto em cursos d'água urbanos da bacia hidrográfica do córrego Jaboticabal. Revista Brasileira de Recursos Hídricos, Porto Alegre, v. 8, 2003.

BRASIL, Resolução CONAMA n ${ }^{\circ}$ 357, de 17 de março de 2005. Classificação de águas, doces, salobras e salinas do Território Nacional. Publicado no D.O.U.

COMPANHIA DE TECNOLOGIA DE SANEAMENTO AMBIENTAL. Indice de Qualidade das Águas. São Paulo, 2007.

LIBÂNIO, M. Fundamentos de qualidade e tratamento de água. Campinas: Átomo, 2005.

LIMBERGER, L.; CORRÊA, T. G. Diagnóstico Ambiental Do Ribeirão Lindóia (Londrina-PR): Aspectos Físico-Químico E Bacteriológico. Revista Eletrônica da Associação dos Geógrafos Brasileiros - Seção Três Lagoas Três Lagoas-MS, V 2 - n. ${ }^{\circ} 2$ - ano 2, Setembro de 2005.

O'CONNOR, D. J. The temporal and spatial distribution of dissolved oxygen in streams. Water Resources. V. 3, 1967.

OTTONELli, M. Diagnóstico da Qualidade da Água do Rio Chiquinha, 